\title{
Acknowledging and building on the work of others
}

\author{
Kenneth Tobin
}

Published online: 5 March 2009

(c) Springer Science+Business Media B.V. 2009

Citing the work of others is part of the scholarly tradition and it is also an acknowledgment that what is known and claimed in an article is socially constituted. One might claim that an idea evolved while a person was alone, contemplating her work and its historical trajectories-eliminating all thoughts about others' programs of work. However, how would she know the origin of her ideas? Undertaking a review of the scholarly works in relevant areas affords awareness of what is happening and connecting one's work to the work of others in relevant fields. Doing this is helpful to authors of articles and also to readers who can then readily situate a publication into a context of other relevant work. I regard it as the authors' responsibility to show an awareness of the field, identify key works, and to explain the connections of what is included in a given article and other identified works.

In Cultural Studies of Science Education (CSSE) we do not encourage the common practice of including lists of citations in parentheses as markers of relevant work in a given area. Instead we ask authors to take the space to show how each cited work fits into the developing thesis of a paper. That is, explain how something specific from a cited source is relevant to the issues being discussed at the time. One test of whether or not a citation is substantive is the extent to which reasons for the citation are apparent to the reader. Of course, it might still be the case that the citation is inappropriate, however, by making the reasons visible, the reader has the chance to judge whether or not the arguments an author is making are warranted.

An important set of connections that often need to be made explicit pertains to how this article connects to other publications from the authors of a paper and to publications of colleagues within the same research group. Self-citation should have a purpose that is clear to the reader. One important reason is to show connections to earlier work in a field and to contemporary work that is to be published elsewhere. In this way, authors can be explicit in showing how what is in a given paper is different than and builds on what has been written elsewhere. This seems highly prudent when a paper is one of many from a given database.

K. Tobin $(\bowtie)$

Urban Education, The Graduate Center of the City University of New York, 365 5th Avenue,

New York, NY 10016-4309, USA

e-mail: ktobin@gc.cuny.edu 
A similar issue can arise when an author publishes many times in ways that are nuanced to her but can be read by an editor as just another paper that reiterates ideas or findings already published. Several years ago, for example, an editor from a leading science education journal complained: "does she ever have an idea that she does not seek to publish?" This comment was made in a context of the editor no longer welcoming submissions from that author because the studies were perceived as not sufficiently different than her previously published articles. This particular issue (and possible similar situations that might arise with CSSE) may be addressed by the author, with a review of (1) what has been done previously (i.e., citing the work of self and others), (2) what this paper contributes that is new, and (3) how the paper relates to publications from the same research group (including self-citation). Similarly, if authors submit very similar pieces to different journals and it is not clear how the parallel works differ, it is initially the authors' responsibility for making the differences clear and showing the relationships among contemporary work through self-citation and careful argument.

An important purpose for citation in CSSE concerns the opportunity to show the genealogy of the authors' standpoints and theoretical frameworks. Some authors in this journal make citations as if they are pointing to scholars who have got it right. These are tantamount to pointing to sources of truth, albeit socially constituted truths. Others, and I am one of them, prefer to use citations as a means to show where our thinking started on a particular topic. For example, when we began to view science learning as cultural production we developed our ideas from the work of Pierre Bourdieu and William Sewell Junior. However, when we cite these scholars we do not intend readers to go to the cited works and find that the ideas presented there have been adopted in a literalist sense. We read what others said and then through many hours of discussion in our research groups we adapt their theories and use them for our scholarly purposes. Over many years, due to the work of many scholars within our research squads, we became aware of others' frameworks and, just as we did with Bourdieu and Sewell, we adapted their ideas to illuminate our research in ways we felt were productive. For more than a decade we read extensively, listened to the voices of others, and learned from the key works of others such as Stuart Hall, Homi Bhabha, Ann Swidler, Kwami Appiah, and Alfred Schutz. When authors in CSSE revealed new ways of thinking about science education, such as WolffMichael Roth's writing on passivity, we read his work on this topic and then studied the work of other scholars who had made a career of doing work in this area. Over time this theoretical work became central in our framework in much the same way that theories on the sociology of emotions and prosody have become central. Hence, when we cite particular works, we are showing the genealogy of our ideas. As authors it is our responsibility to make clear the purpose of citations and ensure that readers get what they need in the text, either by citation or reasoned argument, to make sense of our work-e.g., no gaps in the reasoning, descriptions of terms are semantically adequate, and claims are supported with justifying reasons.

Effective authoring is about communicating with readers. Obviously it is not possible or desirable to cite all literature that is germane to a topic. Nor is it essential to go back to the first person to work on a particular idea. Authors can and should use the literature in ways that fit their standpoints and scholarly projects. As editor-in chief of CSSE I collaborate with the Editorial Board, selected reviewers, and authors to ensure that citations are appropriate for given texts, are used substantively, and effectively contribute to the scholarly works we publish. In raising this issue here, I have done little more than to scratch the surface of an important idea that needs to be further elaborated in our community. What I have made explicit are reasons for the stance we have taken since the 
launching of CSSE. We discourage what we refer to as symbolic citation and return manuscripts for revision when authors use strings of citations in parentheses or fail to work citations into the arguments being advanced in the paper.

\section{In this issue}

Science education in Australia and New Zealand

In this issue of CSSE we continue the tradition of presenting the history of the institutions of science education; on this occasion the Australasian Science Education Research Association (ASERA). Stephen Ritchie assumes editorial responsibility for the publications in this section and his insightful editorial begins the process of laying out the history of ASERA in terms of his own experiences with the organization, first as a novice, then as an experienced researcher, and now as editor-in-chief of Research in Science Education. Following the editorial is a compendium of ten researchers' experiences with ASERA. Finally there is an examination of the work of four Key Contributors, Peter Fensham, Roger Osborne, Campbell McRobbie, and Leonie Rennie. As is clear from these historical accounts, the contributions to science education from Australia and New Zealand have been highly significant for many years.

Premature death of leading science educator

In this issue we publish an article by Sreyashi Jhumki Basu and her colleagues. The article concerns the teaching and learning of physics in a high school in New York City. Two university-based researchers and two of the students from the physics class author the paper collaboratively. Accordingly, one of the contributions of this paper is its attention to voice as well as its substantive focus on critical science agency.

As we finalized the Forum associated with the original article we were saddened to hear that Jhumki had finally lost her battle with cancer. As well as the article and associated Forum pieces, Angela Calabrese Barton has written a Key Contributors article focusing on Jhumki's contributions to science education. In addition, a number of scholars have co-authored an interactive paper that also addresses the research and scholarship of a young scholar who died while still in the early stages of her career.

\section{Coteaching}

This issue contains an important set of papers on learning to teach science and effectively transitioning into the science teaching profession. Beth Wassell and Sarah Kate LaVan continue the research on coteaching as a means of learning to teach science. This work has now been ongoing for more than a decade and is being done throughout the world. The article and associated Forum involve some of the participants in the study, including one of the coteachers and science educators who were university-based researchers and have used coteaching in their university programs and research on its applications.

Science and religion

Picking up on some of the issues I addressed in an editorial published in CSSE (Issue 4, Volume 3), Konstantinos Alexakos examined science and creationism in an Op-Ed article. 
The article addresses a topic that is central to science education, setting the stage for a special issue that will comprise Volume 5, Issue 1. Op-Ed articles are a genre we anticipate as a prominent feature in CSSE. We invite authors to submit Op-Ed articles with an orientation toward the mission of the journal.

\section{Book review}

Rounding out this issue of CSSE is an editorial from Bhaskar Upadhyay, the Book Review Editor for the journal. His editorial invites authors to submit book reviews that are germane to the goals and mission of CSSE and introduces the first review essay published under his editorship. Coincidentally, the book that is reviewed concerns the distinguished contributions of the founding co-editor of this journal, Wolff-Michael Roth, who completes his term as co-editor-in-chief with the publication of Volume 4. As a co-founder of the journal, Michael's contributions will be recognized in the final issue of Volume 4. 